\title{
Analisa Getaran Gedung Berdasarkan Data Microtemor Dengan Bantuan Matlab
}

\author{
Fauzan Sahputra Hasibuan, Sutrisno \\ Institut Teknologi Medan \\ * e-mail: hasibuanf38@gmail.com
}

\begin{abstract}
Abstrak
Penelitian ini bertujuan untuk mengetahui besar nilai frekuensi natural dan besar nilai perioda pada gedung BR lantai 4 Institut Teknologi Medan (ITM). Penelitian ini menggunakan data Microtemor dengan bantuan matlab untuk mendapatkan besar nilai frekuensi natural dan besar nilai perioda pada gedung. Data Microtemor diolah menggunakan data Microtemor yang diperoleh dari hasil penelitian terdahulu yang telah dilakukan sebelumnya pada gedung BR lantai 4 Institut Teknologi Medan (ITM). Dengan cara input data Microtemor dengan bantuan matlab yaitu dengan cara input data Microtemor, selanjutnya dilakukan plotting data Microtemor pada matlab sehingga hasil simulasi untuk mendapatkan besar nilai frekuensi natural dan besar nilai perioda pada gedung didapatkan. Berdasarkan pengolahan data Microtemor dengan bantuan matlab, didapatkan bahwa besar nilai frekuensi natural pada gedung BR lantai 4 Institut Teknologi Medan (ITM) $0,437 \mathrm{~Hz}$ dan besar nilai perioda getaran pada gedung BR lantai 4 Institut Teknologi Medan (ITM) 0,571 detik.
\end{abstract}

Kata Kunci : Getaran, Microtemor, Matlab

(1) \$ Licensees may copy, distribute, display and perform the work and make derivative works and remixes based on it only if they give the author or licensor the credits (attribution) in the manner specified by these. Licensees may copy, distribute, display, and perform the work and make derivative works and remixes based on it only for non-commercial purposes.

\section{PENDAHULUAN}

Getaran dapat bersumber dari aktifitas alam seperti getaran akibat angin, gelombang akibat air laut dan getaran alamiah dari tanah. Getaran lainnya juga dapat disebabkan oleh aktifitas manusia seperti getaran akibat orang berjalan, getaran mesin, getaran akibat arus lalulintas dan sebagainya. (Mendrofa, 2018).

Microtemor merupakan getaran tanah selain gempa bumi, biasa berupa getaran akibat aktivitas manusia seperti getaran akibat orang yang sedang berjalan, getaran mobil, getaran mesin - mesin pabrik dan juga dapat disebabkan oleh aktivitas alam seperti getaran akibat angin, gelombang laut atau getaran alamiah tanah. Microtemor didasarkan pada perekaman ambient noise untuk menentukan parameter karakteristik dinamika dan fungsi perpindahan bangunan.

Jika getaran terjadi secara terus menerus, maka akan menimbulkan kerusakan struktur pada bangun dan dampaknya akan mengakibatkan keruntuhan terhadap gedung. (Kurniawandy, 2015)

Microtemor erat kaitannya dengan gelombang seismic. Microtemor merupakan gelombang yang berupa getaran tanah yang menjalar atau sering disebut dengan gelombang mikroseismik. Pada penerapnnya, Microtemor mengidentifikasi resonansi frekuensi natural pada bangunan dan tanah (Daristari, 2018).

Dalam Penelitian Rianta dkk (2019) juga merancang microtremor monitoring tools menggunakan sensor dalam aplikasi android 
untuk frekuensi alami bangunan. Tujuan penelitian ini untuk melihat rasio resonansi antara tanah dan banguanan. Arakawa (2014) juga menggunakan metode Microtemor untuk evaluasi frekuensi alami bangunan. Penggunaan data micrometer juga dilakukan pada untuk menganalisis karakteristik dinamis pada gedung (Hadianfard, 2017; Gullapalli, dkk, 2021), perilaku tanah (Gosar, 2010), resiko gempa (Gosar, 2012; Isburhan, 2019) dan historical data (Mucciarelli \& Gallipoli, 2001).

Dalam fisika frekuensi diartikan sebagai jumlah banyaknya getaran dalam satu detik atau satu sekon. Teori frekuensi ini oleh Hertz dirumuskan bahwa frekuensi (f) merupakan jumlah getaran $(\mathrm{N})$ dibagi waktu atau periode (T) (Mendrofa, 2018).

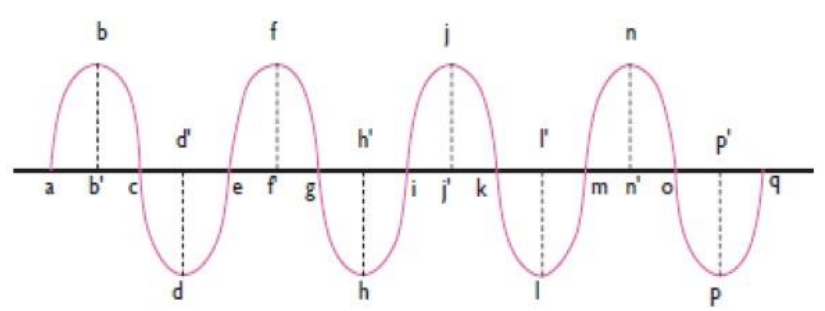

Gambar 1. Gelombang transversal

Pada gelombang transversal (Gambar 1), satu gelombang transversal atas 1 puncak dan 1 lembah. Jarak anatara 2 puncak atau 2 lembah yang berurutan disebut setengah panjang gelombang atau $1 / 2 \lambda$ (lamda).

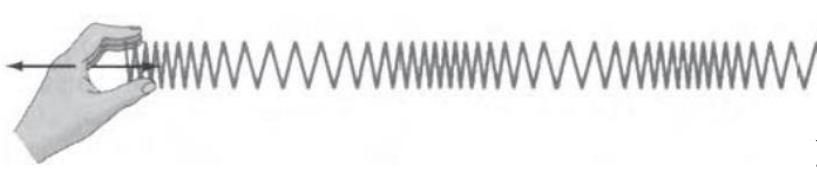

Gambar 2. Gelombang longitudinal

Sedangkan pada gelombang longitudinal (Gambar 2) satu gelombang $(1 \lambda)$ terdiri dari satu rapatan dan satu regangan.

\section{Cepat Rambat Gelombang}

Cepat rambat gelombang adalah jarak yang ditempuh gelombang tiap detik. Hubungan antara $\mathrm{v}, \lambda$ dan $\mathrm{f}$ dituliskan dalam persamaan sebagai berikut.

$V=\frac{\lambda}{T}$ atau $V=f \lambda$
Jika frekuensi berkaitan dengan perioda maka, rumusnya :

$f=\frac{n}{t}$

Jika frekuensi suatu gelombang maka rumusnya :

$f=\frac{\varepsilon}{\lambda}$.

Microtemor adalah getaran tanah yang pada umumnya mempunyai sifat tetap yang memiliki magnito yang kecil. Microtemor biasa berupa getaran akibat aktivitas manusia maupun aktifitas lain, seperti getaran akibat orang berjalan, getaran akibat dari kendaraan, getaran mesin-mesin pabrik, getaran angin, gelombang laut atau getaran aalamiah lainnya. (Darista, 2018).

Microtemor atau yang biasa disebut dengan ambient noise adalah getaran tanah dengan amplitudo Microtemor yang dapat dimbulkan oleh peristiwa alam ataupun buatan, seperti angin gelombang laut atau getaran kendaraan yang bisa menggambarkan kondisi geologi suatu wilayah dekat permukaan.

Matlab merupakan perangkat lunak yang diciptakan oleh perusahaan MathWork, Inc yang berfungsi sebagai bahasa pemograman yang berbasis numerik. Sehingga, matlab banyak digunakan sebagai perangkat lunak yang menawarkan kemudahan dalam penyelesaian permasalahan yang berhubungan dengan angka, numerik ataupun vektor (Wahyuni, 2014)

Matlab merupakan bahasa pemograman yang memperhitungkan angka, numerik, matriks dan serta pemrosesan sinyal dan grafis sehingga dapat divisualisasikan (Khairunnisa, 2017). Kemampuan visualisai ini kemudian digunakan untuk pemrosesan getaran sehingga dihasilkan analisis dalam bentuk kode dan grafis. 


\section{METODE PENELITIAN}

Penelitian ini menggunakan data Microtemor yang telah dilakuakan penelitian sebelumnya pada gedung BR Institut Teknologi Medan
(ITM). Data hasil penelitian Microtemor pada gedung BR Institut Teknologi Medan (ITM) dapat dilihat pada Gambar 3.
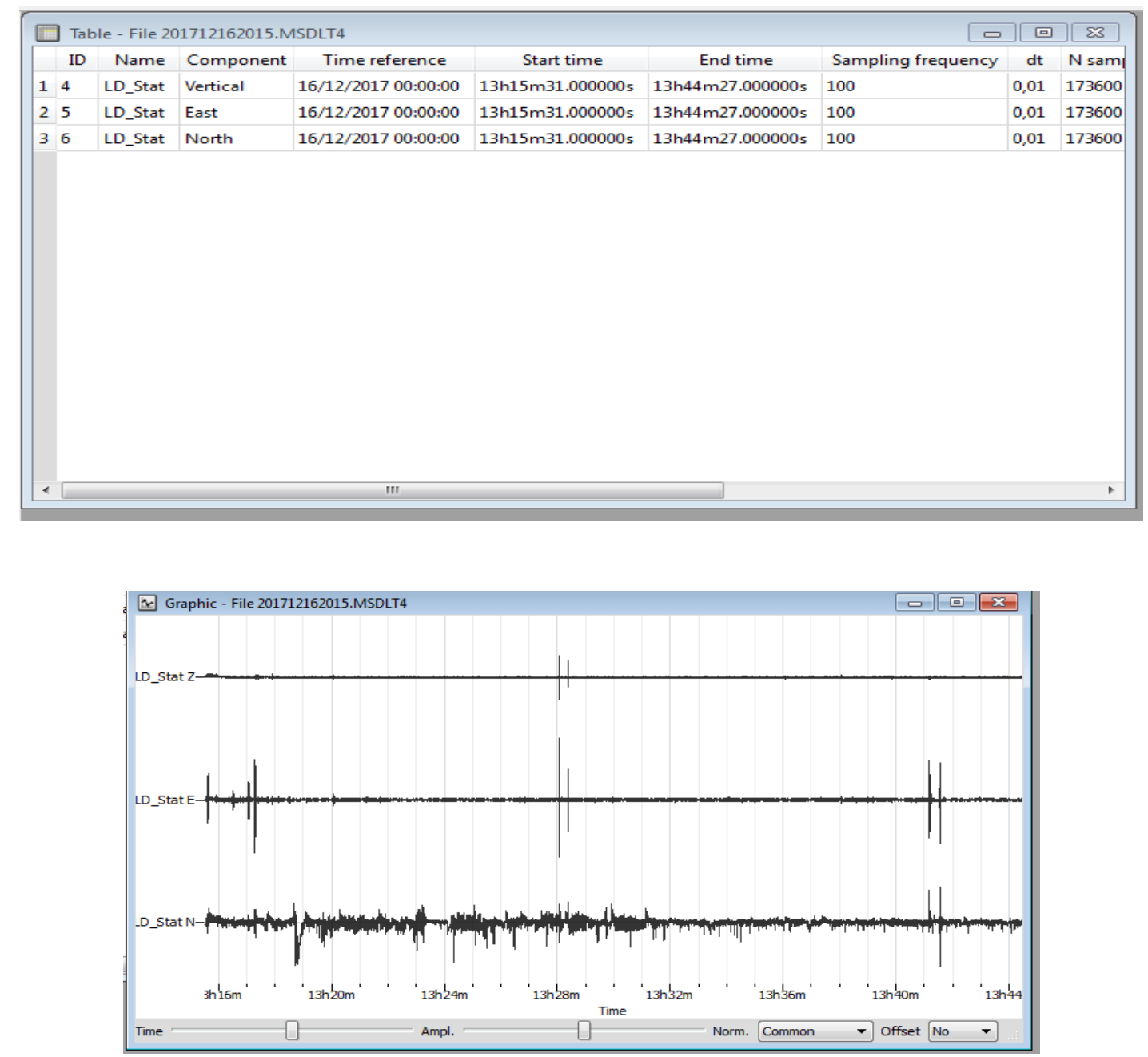

Gambar 3. Data Microtemor

Getaran dapat bersumber dari aktifitas alam seperti getaran akibat angun, gelombang akibat air laut getaran alamiah dari tanah. Getaran lainnya juga dapat disebabkan oleh aktifitas manusia seperti getaran akibat orang berjalan, getaran mesin, getaran akibat arus lalulintas dan sebagainya.

\section{HASIL DAN PEMBAHASAN}

Perhitungan Frekuensi dan Perioda

Dilakukan perhitungan besar nilai frekuensi natural dan besar nilai perioda pada gedung BR lantai 4 Institut Teknologi Medan (ITM) sebagai berikut.

Diketahui :

Berdasarkan dari hasil simulasi data Microtemor maka didapatkan nilai : 
$\mathrm{t}=6-2=4 \operatorname{detik}(\mathrm{s})$

Frekuensi $(f)$

$=\frac{n}{t}$ atau $\frac{1}{t}=\frac{n}{t}=\frac{\frac{\pi}{4}}{4 s}=\frac{7}{4 s} \times \frac{1}{4 s}$

$=\frac{7}{16 s}=0,437$ Hertz

Perioda $(T)$

$=\frac{t}{n}$ atau $\frac{1}{f}=\frac{t}{n}=\frac{4}{1 \frac{8}{4}}=0,571$ detik
Hasil Analisa Data Microtemor dengan Bantuan Matlab dapat terlihat pada Gambar 4.

Perintah export import data matlab berfungsi untuk menganalisis data yang dihasilkan

aplikasi lain maupun untuk menganalisis data yang dihasilkan matlab untuk dianalisisdengan aplikasi lain. Data import dan export dapat berupa data numerik, gambar, audio, grafik maupun teks. Pada kali ini akan digunakan data Microtemor untuk mengetahui frekuensi dan perioda dengan bantuan matlab R2014a.
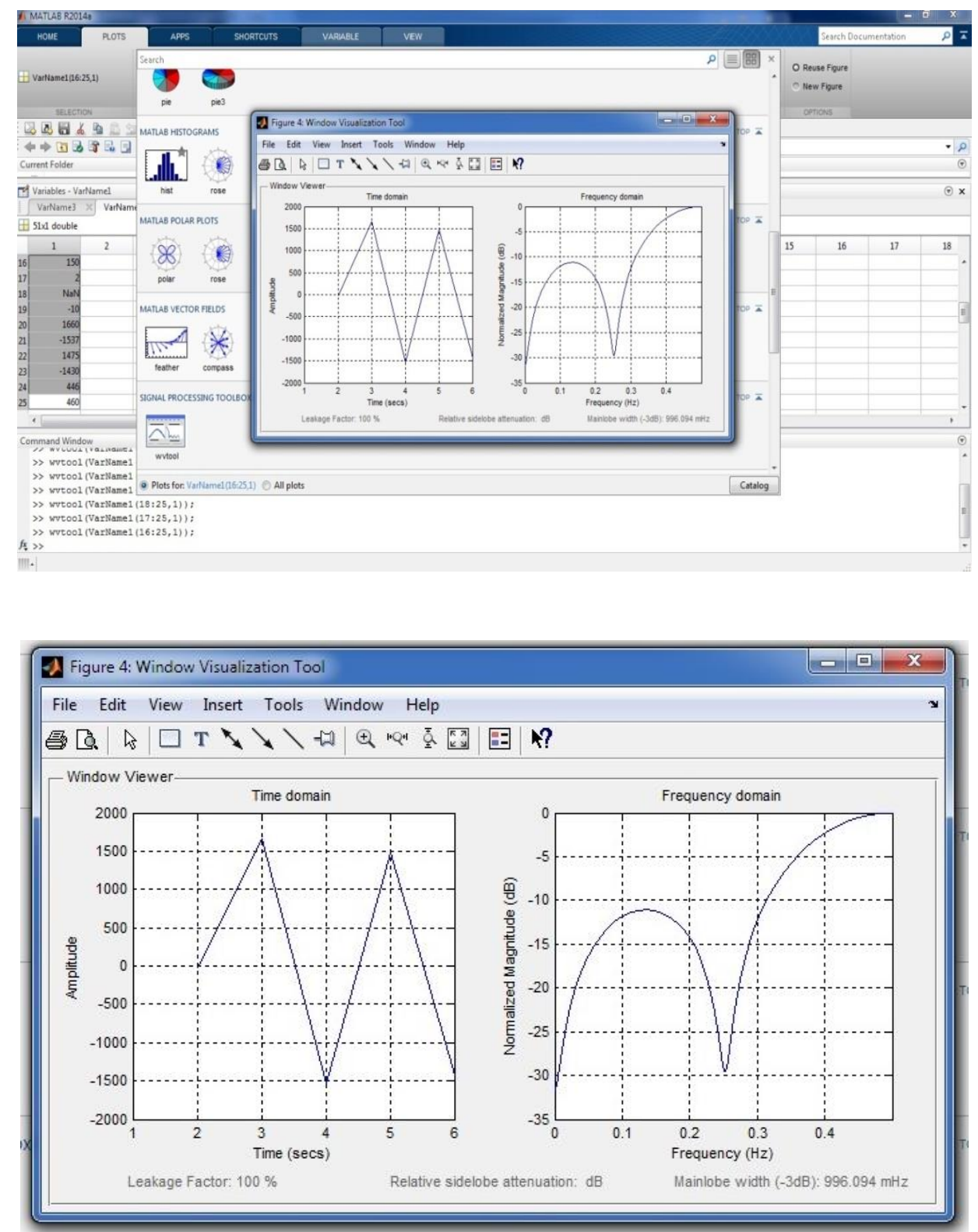

Gambar 4. Hasil Plotting data 


\section{SIMPULAN}

Dari hasil penelitian yang telah dilakukan didapatkan besar nilai frekuensi natural getaran gedung BR lantai 4 Institut Teknologi Medan (ITM) berdasarkan data Microtemor adalah 0,437 Hertz. Berdasarkan kurva puncak percepatan yang disarankan untuk kenyamanan manusia terhadap vibrasi batas limit frekuensi adalah $4 \mathrm{~Hz}$. (ISO 2631-2, 1989). Dengan ini diambil kesimpulan bahwa gedung BR lantai 4 Institut Teknologi Medan (ITM) dinyatakan aman.

\section{DAFTAR PUSTAKA}

Arakawa, T., \& Yamamoto, K. (2004). Frequencies and damping ratios of a high rise building based on microtremor measurement. In Proc., 13th World Conference on Earthquake Engineering.

Daristari. D., (2018). Resonansi Bangunan Dengan Analisis Mikrotremore Di Dusu Patuk Kunung Kidul.

Gosar, A., Rošer, J., Motnikar, B. Š., \& Zupančič, P. (2010). Microtremor study of site effects and soil-structure resonance in the city of Ljubljana (central Slovenia). Bulletin of earthquake engineering, 8(3), 571-592.

Gosar, A. (2012). Determination of masonry building fundamental frequencies in five Slovenian towns by microtremor excitation and implications for seismic risk assessment. Natural hazards, 62(3), 1059-1079.

Gullapalli, V. L., RaghuNandanKumar, R., \& Reddy, G. R. (2021). Assessment of Antenna Mounting Building Structural Strength using Microtremor Analysis. In IOP Conference Series: Materials Science and Engineering (Vol. 1197, No. 1, p. 012057). IOP Publishing.

Hadianfard, M. A., Rabiee, R., \& Sarshad, A. (2017). Assessment of vulnerability and dynamic characteristics of a historical building using microtremor measurements. International Journal of Civil Engineering, 15(2), 175-183.

Irawan. A., (2012). Buku Pintar Pemrograman Matlab.

ISO 2631-2. (1989), kurva Puncak Percepatan Yang Disarankan Untuk Dengan Kenyamanan Manusia Terhadap Vibrasi.

Isburhan, R. W. P., Nuraeni, G., Ry, R. V., Yudistira, T., Cipta, A., \& Cummins, P. (2019, August). Horizontal-to-vertical spectral ratio (HVSR) method for earthquake risk determination of Jakarta City with microtremor data. In IOP Conference Series: Earth and Environmental Science (Vol. 318, No. 1, p. 012033). IOP Publishing.

Khairunnisa. (2017). Analisis Dan Simulasi Gelombang Berulang Komplek Dengan Menggunakan Bahasa Pemrograman Matlab.

Kurniawandy. A., (2015). Evaluasi Kerentanan Bangunan Terhadap Gempa Bumi Dengan Rapid Visual Screnning (RVS) Terhadap Fema 154.

Riantana, R., \& Triyono, A. (2019). Design Of Microtremor Monitoring Tools Using Accelerometer Sensor On Android Mobile To Determine The Natural Building Frequency In UNS Library. In Journal of Physics: Conference Series (Vol. 1204, No. 1, p. 012103). IOP Publishing.

Sidabutar. H., (2019). Analisa Struktur Portal Akibat Gempa Dengan Metode Analisa Riwayat Waktu Pada Gedung Jabal Nur UPT Asrama Haji Medan.

Mendrofa.Y., (2018). Analisa Frekuensi Natural Gedung Dengan Metode Fast Fourier (FFT).

Mucciarelli, M., \& Gallipoli, M. R. (2001). A critical review of 10 years of 
microtremor HVSR technique. Boll. Geof. Teor. Appl, 42(3-4), 255-266.

Sitorus. N., (2000). Teknik Geofisika, Fakultas Teknik Sipil dan Perencanaan Institut Teknologi Sepuluh November.

Wahyuni. A., (2014). Matlab Thr Language Of Technical Computing. Natick The MathWork, Inc.

Utami. Z., (2017). Analisis Indeks Seismik Berdasarkan Pengukuran Sinyal
Microtemor Di Kecamatan Prambanan

Dan Kecamatan Ganti Warno Kabupaten Klaten.

Yasid, S., (2004). Pengaruh Frekuensi Gelombang Bunyi Terhadap Perilaku Lalat Rumah (Musca Domestica). 